\title{
O CONHECIMENTO E AS PRÁTICAS DO ANALISTA DO COMPORTAMENTO
}

KNOWLEDGE AND BEHAVIOR ANALYSTS PRACTICES

\author{
Henrique Valle Belo Ribeiro Angelo ${ }^{1}$ \\ UNIVERSIDADE PRESBITERIANA MACKENZIE \\ Camila Muchon de Melo ${ }^{2}$ \\ UNIVERSIDADE FEDERAL DE SÃO CARLOS \\ Ricardo Corrêa Martone ${ }^{3}$ \\ NÚCLEO PARADIGMA DE ANÁLISE DO COMPORTAMENTO
}

\section{RESUMO}

O artigo "Behavior analysis and the social construction of knowledge", de Bernard Guerin, é apresentado ressaltando sua importância para analistas do comportamento que trabalham tanto com análises institucionais quanto clínicas.

Palavras-chave: Guerin, construção social do conhecimento, comportamento verbal, psicologia social.

\begin{abstract}
The paper "Behavior analysis and the social construction of knowledge" of Bernard Guerin is presented pinpointing its relevancy to the behavior analysts who work with clinical or institutional analysis.

Keywords: Guerin, social construction of knowledge, verbal behavior, social psychology.
\end{abstract}

$\mathrm{O}$ artigo "Behavior analysis and the social construction of knowledge", de Bernard Guerin, foi publicado em 1992 em uma edição especial da revista American Psychologist. Nesse trabalho, Guerin realiza uma aproximação entre a psicologia social e a análise do comportamento, apontando que alguns fenômenos estudados tradicionalmente pela primeira poderiam também ser alvo de interesse de analistas do comportamento.

Guerin se valeu dos pressupostos teóricos de dois importantes autores, Serge Moscovici e Kenneth Gergen, autores esses que desenvolveram o que se conhece por "cons- trutivismo social", enfatizando que grande parte dos fenômenos tratados por essa teoria pode ser analisada a partir de uma abordagem skinneriana da linguagem.

A premissa principal do trabalho de Guerin aponta para a natureza eminentemente (mas não só) social dos estímulos ambientais (que também inclui o comportamento do outro como estímulo social para o comportamento de alguém), assim como do produto da interação do comportamento de múltiplos indivíduos. Tais interações, por serem sociais, são constituídas, em sua grande maioria, por contingências verbais. Assim, o que Moscovi-

\footnotetext{
${ }^{1}$ Graduando pela Universidade Presbiteriana Mackenzie.E-mail: rick.angelo@hotmail.com

${ }^{2}$ Doutora pela Universidade Federal de São Carlos. E-mail: camuchon@hotmail.com

${ }^{3}$ Núcleo Paradigma de Análise do Comportamento. E-mail: rcmartone@gmail.com. Endereço para correspondência: QMSW 05 Lt.2 B1. D apto. 105, Ed. Montblanc. Sudoeste, Brasília/DF, 70680-500. E-mail: borgesmoreira@gmail.com. Tels.: (61) 8154-8063 / (61) 3253-9147.
} 
ci e Gergen denominam "construção social" e/ou "representação social", a análise skinneriana compreenderia como o resultado da interação de alguns operantes verbais, a saber, autoclíticos, tatos e intraverbais.

O trabalho de Guerin chama a atenção para dois aspectos cruciais quando a temática do que se quer analisar se encontra na dimensão social. Primeiro, analistas do comportamento apresentam instrumental teórico capaz de abordar fenômenos de tal complexidade e que envolvem o comportamento de inúmeros agentes sociais. Segundo, grande parte do que conhecemos como "construção social" ou "representação social" apresenta base empírica e é o resultado de contingências verbais que podem ser identificadas. Assim, "representações sociais" aparentam pertencer a uma natureza deslocada da realidade (mundos virtuais). E, se há algum problema com "mundos virtuais", é na esfera verbal-relacional que devemos intervir.

Um vasto campo se abre ao analista do comportamento que desejar seguir por esse caminho. Por exemplo, o papel do comportamento verbal na transmissão de práticas culturais, já presente, ainda de forma muito incipiente, na literatura da análise do comportamento, assim como a importância da análise do comportamento verbal em uma sessão clínica.

Uma das conclusões que se podem tirar do trabalho de Guerin é que o discurso das pessoas está relacionado com um conhe- cimento construído socialmente, quando comportamentos verbais, como descrições imprecisas do ambiente, ou ainda o reforço de cadeias intraverbais que "descrevem" ilusões são reforçados como dados fiéis do ambiente.

$\mathrm{O}$ autor ainda atribui um papel importante à mídia de massa na construção do conhecimento e compara o controle ético em diferentes momentos da história. A proposta de Guerin, apesar de ter sido escrita no início dos anos 1990, mostra-se extremamente atual e de suma importância para a análise do comportamento.

Este trabalho, além de prover instrumental teórico para a análise do comportamento aplicada, também nos mostra que existem trabalhos interessantes em outras abordagens. Se tiverem olhos críticos e uma fundamentação teórica consistente, analistas do comportamento podem beneficiar-se dos estudos e dos dados originados de outras pesquisas, ainda que com fundamentação teórica e/ ou epistemológica distintas das apresentadas pela análise do comportamento. Desse modo, o artigo de Guerin apresenta-se, também, como um convite para análises desse tipo.

\section{REFERÊNCIA}

Guerin, B. (1992). Behavior analysis and the social construction of knowledge. American Psychologist, 47(11), 1423-1432. 